\title{
Accuracy in Diagnosis of Celiac Disease Without Biopsies in Clinical Practice
}

Katharina Julia Werkstetter, ${ }^{1}$ IIma Rita Korponay-Szabó, ${ }^{2,3}$ Alina Popp, ${ }^{3,4}$ Vincenzo Villanacci, ${ }^{5}$ Marianna Salemme, ${ }^{5}$ Gabriele Heilig, ${ }^{1}$ Søren Thue Lillevang, ${ }^{6}$ Maria Luisa Mearin, Carmen Ribes-Koninckx, ${ }^{8}$ Adrian Thomas, ${ }^{9}$ Riccardo Troncone, ${ }^{10}$ Birgit Filipiak, ${ }^{1}$ Markku Mäki, ${ }^{3}$ Judit Gyimesi, ${ }^{2}$ Mehri Najafi, ${ }^{11}$ Jernej Dolinšek, ${ }^{12}$ Stine Dydensborg Sander, ${ }^{13}$ Renata Auricchio, ${ }^{10}$ Alexandra Papadopoulou, ${ }^{14}$ Andreas Vécsei, ${ }^{15}$ Peter Szitanyi, ${ }^{16}$ Ester Donat, ${ }^{8}$ Rafaella Nenna, ${ }^{17}$ Philippe Alliet, ${ }^{18}$ Francesca Penagini, ${ }^{19}$ Hélène Garnier-Lengliné, ${ }^{20}$ Gemma Castillejo, ${ }^{21}$ Kalle Kurppa, ${ }^{3}$ Raanan Shamir, ${ }^{22}$ Almuthe Christine Hauer, ${ }^{23}$ Françoise Smets, ${ }^{24}$ Susana Corujeira, ${ }^{25}$ Myriam van Winckel, ${ }^{26}$ Stefan Buderus, ${ }^{27}$ Sonny Chong, ${ }^{28}$ Steffen Husby, ${ }^{13}$ and Sibylle Koletzko, ${ }^{1}$ on behalf of the ProCeDE study group

\footnotetext{
${ }^{1}$ Dr. von Hauner Children's Hospital, Department of Pediatrics, University Hospital, LMU Munich, Munich, Germany; ${ }^{2}$ Celiac Disease Center Heim Pál Children's Hospital, Budapest and Department of Pediatrics, University of Debrecen, Debrecen, Hungary; ${ }^{3}$ Center for Child Health Research, University of Tampere and Tampere University Hospital, Tampere, Finland; "University of Medicine and Pharmacy "Carol Davila" and National Institute for Mother and Child Health "Alessandrescu-Rusescu," Bucharest, Romania; ${ }^{5}$ Institute of Pathology, Spedali Civili, Brescia, Italy; ${ }^{6}$ Department of Clinical Immunology, Odense University Hospital, Odense, Denmark; ${ }^{7}$ Department of Pediatrics, Leiden University Medical Center, Leiden, the Netherlands; ${ }^{8}$ Department of Pediatric Gastroenterology and Hepatology, La Fe University Hospital, Valencia, Spain; ${ }^{9}$ Department of Pediatric Gastroenterology, Royal Manchester Children's Hospital, Manchester, United Kingdom; ${ }^{10}$ Department of Translational Medical Sciences \& European Laboratory for the Investigation of Food-Induced Diseases, University Federico II, Naples, Italy; ${ }^{11}$ Department of Pediatric Gastroenterology \& Hepatology, Children's Medical Center, Tehran University of Medical Sciences, Tehran, Iran; ${ }^{12}$ Department of Pediatrics, University Medical Center (UMC), Maribor, Slovenia; ${ }^{13}$ Hans Christian Andersen Children's Hospital, Odense University Hospital, Odense, Denmark; ${ }^{14}$ Division of Gastroenterology, Hepatology and Nutrition, First Department of Pediatrics, Children's Hospitals "Agia Sophia," University of Athens, Athens, Greece; ${ }^{15}$ Gastroenterology Outpatient Clinic, St. Anna Children's Hospital, Medical University Vienna, Vienna, Austria; ${ }^{16}$ Department of Pediatrics and Adolescent Medicine, First Faculty of Medicine and General Teaching Hospital, Charles University, Prague, Czech Republic; ${ }^{17}$ Department of Pediatrics, Sapienza University of Rome, Rome, Italy; ${ }^{18}$ Department of Pediatrics, Jessa Hospital, Hasselt, Belgium; ${ }^{19}$ Department of Pediatric Gastroenterology, Addenbrookes Hospital, Cambridge, United Kingdom; ${ }^{20}$ Department of Pediatric Gastroenterology, Hepatology and Nutrition, Hôpital Necker-Enfants Malades, Paris, France; ${ }^{21}$ Department of Pediatric Gastroenterology and Nutrition, Hospital Universitari Sant Joan, Reus, Spain; ${ }^{22}$ Institute of Gastroenterology, Nutrition and Liver Diseases, Schneider Children's Medical Center of Israel, Sackler Faculty of Medicine, Tel Aviv University, Tel Aviv, Israel; ${ }^{23}$ Department of Pediatrics, Medical University of Graz, Graz, Austria; ${ }^{24}$ Université Catholique de Louvain, IREC, PEDI, Cliniques universitaires Saint Luc, Brussels, Belgium; ${ }^{25}$ Department of Pediatric Gastroenterology, Hospital S. João, Porto, Portugal; ${ }^{26}$ Department of Pediatric Gastroenterology, Hepatology and Nutrition, Ghent University Hospital, Ghent, Belgium; ${ }^{27}$ Department of Pediatrics, St. Marien Hospital, Bonn, Germany; and ${ }^{28}$ Queen Mary's Hospital for Children, Carshalton, United Kingdom
}

BACKGROUND \& AIMS: The guidelines of the European Society of Pediatric Gastroenterology, Hepatology, and Nutrition allow for diagnosis of celiac disease without biopsies in children with symptoms and levels of immunoglobulin A against tissue-transglutaminase (TGA-IgA) 10-fold or more the upper limit of normal (ULN), confirmed by detection of endomysium antibodies (EMA) and positivity for HLA-DQ2/DQ8. We performed a large, international prospective study to validate this approach. METHODS: We collected data from consecutive pediatric patients (18 years or younger) on a gluten-containing diet who tested positive for TGA-IgA from November 2011 through May 2014, seen at 33 pediatric gastroenterology units in 21 countries. Local centers recorded symptoms; measurements of total IgA, TGA, and EMA; and histopathology findings from duodenal biopsies. Children were considered to have malabsorption if they had chronic diarrhea, weight loss (or insufficient gain), growth failure, or anemia. We directly compared central findings from 16 antibody tests (8 for TGA-IgA, 1 for TGA-IgG, 6 for IgG against deamidated gliadin peptides, and 1 for EMA, from 5 different manufacturers), 2 HLA-DQ2/DQ8 tests from 2 manufacturers, and histopathology findings from the reference pathologist. Final diagnoses were based on local and central results. If all local and central results were concordant for celiac disease, cases were classified as proven celiac disease. Patients with only a low level of TGA-IgA (threefold or less the ULN) but no other results indicating celiac disease were classified as no celiac disease. Central histomorphometry analyses were performed on all other biopsies and cases were carefully reviewed in a blinded manner. Inconclusive cases were regarded as not having celiac disease for calculation of diagnostic accuracy. The primary aim was to determine whether the nonbiopsy approach identifies children with celiac disease with a positive predictive value (PPV) above $99 \%$ in clinical practice. Secondary aims included comparing 


\section{EDITOR'S NOTES \\ BACKGROUND AND CONTEXT}

In 2012, the European pediatric guideline proposed a nonbiopsy approach for celiac disease diagnosis if certain criteria are fulfilled.

\section{NEW FINDINGS}

If TGA-IgA is higher than 10-fold the upper limit of normal and endomysium autoantibodies are positive in a $2^{\text {nd }}$ blood sample, the non-biopsy approach is reliable with a PPV >99\%. HLA-DQ2/DQ8 typing can be omitted.

\section{LIMITATIONS}

The conclusions apply for the 10 different TGA tests used in the study and for symptomatic pediatric but not for adults patients.

\section{IMPACT}

More than $50 \%$ children and adolescents with celiac disease can be diagnosed without biopsies, avoiding the burden of upper endoscopy with anesthesia and saving health care costs.

performance of different serological tests and to determine whether the suggested criteria can be simplified. RESULTS: Of 803 children recruited for the study, 96 were excluded due to incomplete data, low level of IgA, or poor-quality biopsies. In the remaining 707 children $(65.1 \%$ girls; median age, 6.2 years), 645 were diagnosed with celiac disease, 46 were found not to have celiac disease, and 16 had inconclusive results. Findings from local laboratories of TGA-IgA 10-fold or more the ULN, a positive result from the test for EMA, and any symptom identified children with celiac disease $(n=399)$ with a PPV of 99.75 (95\% confidence interval [CI], 98.61-99.99); the PPV was 100.00 (95\% CI, 98.68-100.00) when only malabsorption symptoms were used instead of any symptom $(n=278)$. Inclusion of HLA analyses did not increase accuracy. Findings from central laboratories differed greatly for patients with lower levels of antibodies, but when levels of TGA-IgA were 10 -fold or more the ULN, PPVs ranged from $99.63(95 \% \mathrm{CI}$, 98.67-99.96) to 100.00 (95\% CI, 99.23-100.00). CONCLUSIONS: Children can be accurately diagnosed with celiac disease without biopsy analysis. Diagnosis based on level of TGA-IgA 10-fold or more the ULN, a positive result from the EMA tests in a second blood sample, and the presence of at least 1 symptom could avoid risks and costs of endoscopy for more than half the children with celiac disease worldwide. HLA analysis is not required for accurate diagnosis. Clinical Trial Registration no: DRKS00003555.

Keywords: ESPGHAN; Nonbiopsy Approach; Autoimmunity; ProCeDE Study.

C eliac disease (CD) is an autoimmune disorder triggered by gluten and related prolamines in genetically susceptible individuals carrying the HLA-DQ2 and/or -DQ8 alleles. ${ }^{1}$ CD is characterized by enteropathy and presence of CD-specific autoantibodies against tissuetransglutaminase (transglutaminase type 2 [TGA]) and endomysium (EMA). The prevalence of CD in Europe and North America is approximately $1 \%$ to $2 \%{ }^{2}$ with higher rates in first-degree relatives of patients with $\mathrm{CD}$ and individuals with associated disorders such as type 1 diabetes mellitus (T1DM) or trisomy $21^{3}$

Until 2012, the histological proof of villous atrophy on small bowel biopsies was obligatory for the diagnosis of CD. During the past decade, unambiguousness of histopathology was questioned, ${ }^{4-6}$ and a strong correlation between TGA titer levels and severity of mucosal lesions was recognized. ${ }^{7}$

In 2012, the European Society of Pediatric Gastroenterology, Hepatology and Nutrition (ESPGHAN) published new diagnostic criteria for CD. ${ }^{1}$

These criteria gave pediatric gastroenterologists the option to diagnose $\mathrm{CD}$ without biopsies in children with symptoms indicative for $\mathrm{CD}$, serum TGA-immunoglobulin (Ig)A titers above 10 times upper limit of normal $(\geq 10 x U L N)$ in a calibration-curve-based test, positive EMAIgA in a second blood sample, and positive HLA-risk alleles. The evidence for this approach was mostly based on retrospective data or small single-center studies.

Our Prospective Celiac Disease Diagnostic Evaluation study (ProCeDE) aimed to evaluate in a multicenter setting whether this nonbiopsy approach allows a correct diagnosis in clinical practice with a positive predictive value (PPV) above 99\% when all required conditions are fulfilled.

Secondary aims included determining the accuracies of various TGA tests and their reliability to predict CD if levels are $\geq 10 x U L N$ as well as the impact of HLA-typing, EMAIgA, and type of symptoms on CD diagnosis without biopsies.

\section{Methods}

\section{Study Design and Participants}

From November 2011 to May 2014, 33 pediatric gastroenterology units from 21 countries (Europe, Middle East) recruited consecutive patients younger than 19 years on a gluten-containing diet, with positive TGA results analyzed in their own or external laboratories. Exclusion criteria comprised refusal to duodenal biopsies, primary or secondary immunodeficiency, malignancy, or previous diagnosis of CD.

Recruited patients were excluded from the analysis if local and central HLA results were unavailable, serum or histology slides were not provided for central assessment, biopsies were unreadable due to poor quality, total IgA was low, inclusion criteria were violated, or consent was withdrawn.

Abbreviations used in this paper: $\mathrm{CD}$, celiac disease; $\mathrm{Cl}$, confidence interval; DGP, antibodies against deamidated gliadin peptides; EMA endomysium antibodies; HLA, human leukocyte antigen; Ig, immunoglobulin; T1DM, type 1 diabetes mellitus; TGA, autoantibodies against tissue-transglutaminase; PPV, positive predictive value; ULN, upper limit of normal.

Most current article

\section{(C) 2017 by the AGA Institute} 0016-5085/\$36.00

http://dx.doi.org/10.1053/j.gastro.2017.06.002 


\section{Local Workup}

Obligatory diagnostic workup at the local site included serology (total IgA, TGA, EMA) and histopathology from duodenal biopsies. Collected data comprised family, medical, and dietary history; symptoms; physical examination; basic laboratory parameters; most recent local TGA- and EMA-IgA results, including date of measurement and name of test-kit/ manufacturer with respective ULN (Supplementary Tables 1 and 2); local HLA-typing for DQ2/DQ8 if performed; endoscopy findings; histopathology, including Marsh-Oberhuber staging $^{8,9}$; and local diagnosis (CD, no $\mathrm{CD}$, unclear). Data entry was completed into study database before central analysis started. Local serology should have been done a maximum 2 weeks before or at biopsy. Serum for central laboratory, DNA, and histology slides were collected at time of biopsy.

A child was considered to have low/deficient total IgA if serum concentration was $<0.25 \mathrm{~g} / \mathrm{L}$, negative TGA-IgA but positive IgG-based antibodies (see Supplementary Methods, Section 1.8).

According to clinical presentation, patients were stratified into 3 groups: malabsorption symptoms, other clinical symptoms, and no symptoms.

Malabsorption was considered with at least 1 of the following symptoms: chronic diarrhea, weight loss or insufficient gain, growth failure, and anemia (hemoglobin below reference value for age and sex).

\section{Central Analyses}

All investigators performing central analyses were blinded toward available local and central results. Overall, 16 antibody tests (8 TGA-IgA, 1 TGA-IgG, 6 DGP-IgG, and 1 EMA) from 5 different manufacturers were analyzed head-to-head (Supplementary Methods, Section 1.5.2; Supplementary Tables 3 and 4). Details and results on DGP-IgG tests are shown in the supplementary tables only.

Immunofluorescent analysis of EMA-IgA was performed by one experienced technician (G.H.) with serum dilutions of 1:5, $1: 10,1: 100,1: 1000$, and $1: 2.5$ if the $1: 5$ dilution was negative. A signal in 1:2.5 dilution or higher was considered positive (Supplementary Methods, Section 1.5.1).

All tests were performed according to the manufacturer's instructions in a single run either on automated, calibrated enzyme-linked immunosorbent assay systems (EUROIMMUN Analyzer I; EUROIMMUN Medizinische Labordiagnostika AG, Lübeck, Germany) or on the respective automatized systems (Phadia250, Thermo Fisher, Waltham, MA; QuantaFlash, INOVA Diagnostics, San Diego, CA). Standard curves were available for all tests. Two different HLA-DQ2/DQ8-typing approaches were applied (Supplementary Methods, Section 1.6) and results stratified in 5 HLA-risk groups. ${ }^{10,11}$ Negative HLA status was defined if none of the CD-related risk alleles or only alleles encoding the $\alpha$-subunit (without the corresponding $\beta$-subunit) of DQ2 and/or DQ8 were present. ${ }^{12}$ In patients with negative HLA status but positive central serology and histopathology, a third HLA-typing for rare risk alleles was performed from a new blood sample. If central HLA-typing was not possible for ethical or technical reasons, local results were used.

The reference pathologist reported histology on provided slides (hematoxylin-eosin and CD3+ immunostaining), including Marsh-Oberhuber-staging., ${ }^{8,9}$ Unclear cases were blindly reviewed by a second reference pathologist. If specimens were nonevaluable, the paraffin-embedded biopsy blocks were requested for reoriented cuttings and blindly evaluated, including morphometry.

\section{Central Diagnosis}

The final central diagnosis for each patient was (1) proven $\mathrm{CD},(2)$ no $\mathrm{CD}$, or (3) inconclusive case. $\mathrm{CD}$ was proven if HLADQ2/DQ8, local TGA-IgA, and local and/or central EMA-IgA were all positive, and both local and reference pathologists reported at least Marsh 2 staging.

CD was excluded if HLA-DQ2/DQ8 was negative, local TGA-IgA below 3xULN, local and central EMA-IgA were negative, and local and central pathologists reported Marsh 0 or 1.

Patients not meeting these criteria were initially considered as unclear and histopathology was revised as described previously. The diagnostic committee reviewed each unclear case and voted in a Delphi process (Supplementary Methods, Section 1.9; Supplementary Figure 2). If this did not allow a clear diagnosis, cases were finally regarded as inconclusive.

\section{Criteria for CD Diagnosis Without Biopsies}

For local and central TGA levels, the multiple of the respective ULN was calculated and stratified into high positive $(\geq 10 \mathrm{xULN})$ or low to moderate positive ( $>1$ to $<10 \mathrm{xULN})$. For tests with a given gray zone, the lower bound was used as ULN. To evaluate whether the nonbiopsy approach would contradict the final central diagnosis, we considered the combination of high local TGA, positive local EMA-IgA, positive central HLA status, and symptoms. Furthermore, the diagnostic accuracies of high central TGA $(\geq 10 x U L N)$ for each included commercial kit alone and in combinations with HLA status, EMA results, and symptoms were calculated against the central diagnosis as reference.

\section{Study Oversight}

The study was approved by the ethics committees of each participating center. Written informed consent was obtained by legal guardians and patients as appropriate for age. The study was cofunded by industry (EUROIMMUN Medizinische Labordiagnostika AG; Eurospital, Trieste, Italy; INOVA Diagnostics; R-Biopharm, Darmstadt, Germany; Phadia/ Thermo Fisher; Dr. Schär GmbH, Apolda, Germany) and nonprofit organizations (ESPGHAN, AOK Bayern health insurance, and CD patient organizations from Denmark, Finland, Germany, Hungary, Italy, the Netherlands, and the United Kingdom). Funding partners were not involved in study design, recruitment, data collection, analysis, and interpretation or writing of the manuscript.

All authors had access to the study data and reviewed and approved the final manuscript. ProCeDE is registered at the German Registry for Clinical Trials, Reg-No DRKS00003555.

\section{Statistical Analyses}

With 701 participants, the study had $80 \%$ power at $5 \%$ significance level to detect a PPV of more than $97 \%$ for most test scenarios. Assuming an estimated ratio (PPV) $\geq 99 \%$ and using the exact binomial distribution, a sample size of 348 with power of $86.1 \%$ was calculated. 
When sequential test design was considered (by ADDPlan Software, Cologne, Germany), the needed number increased to 357 . The interim analysis with the first 200 patients showed that the proportion of cases potentially qualifying for omitting biopsies with local parameter ranged between $50 \%$ and $65 \%$. Therefore, we planned to recruit a minimum of 700 patients.

Mean and standard deviation or median and range and frequency in percentage were indicated.

For main analysis of diagnostic accuracies, all inconclusive cases were considered as no $\mathrm{CD}$, or were excluded in a subsample analysis.

Sensitivity, specificity, PPVs, and positive likelihood ratios for different scenarios (TGA $\geq 10 x U L N$ alone and in combination with other criteria) were calculated with $95 \%$ confidence intervals (CI) using binominal distribution (Copper-Pearson CI). Sensitivity expresses the proportion of patients qualifying for the nonbiopsy approach.

All statistical analyses were done by B.F. and K.W. using SAS 9.3 (SAS Institute Inc., Cary, NC).

\section{Results}

Of 968 eligible patients, 803 (83.0\%) were recruited. Ninety-six patients were excluded, 36 due to nonevaluable histology and 17 due to low total IgA (Figure 1; Supplementary Tables 5, 6, and 8). From 1 center, all 12 patients had to be excluded due to incomplete sample sets. In the final cohort $(n=707), 399$ patients $(56.4 \%)$ qualified for the nonbiopsy approach according to ESPGHAN guidelines. Basic characteristics are shown in Table 1 and Supplementary Table 7.

In 29 patients, local TGA-IgA was negative at time of biopsy, but all had positive TGA-IgA before referral (Supplementary Table 9). Local EMA-IgA was available in 681 and central EMA-IgA in 704 patients. Forty-five patients $(7.6 \%)$ were biopsied with capsule. In those undergoing endoscopy, macroscopic findings were reported on a standardized questionnaire in 653 patients. Erosive esophagitis was present in $3.7 \%$, but no case of eosinophilic esophagitis was reported. Gastric erosions were found in $3.2 \%$, duodenal erosions in $6.3 \%$, and a duodenal ulcer in $0.3 \%$ of the patients. Helicobacter pylori status was available in 441 patients; of those, 21 (4.5\%) were positive. The local pathologist provided Marsh classification in 676 cases. Compared with the central pathologist, there was disagreement regarding the histologic judgment of CD (Marsh 2 or 3) and no CD (Marsh 0 or 1) in $48(7.1 \%)$ of 676 patients (Supplementary Tables 20 and 21). EurGenRisk-typing for HLA-DQ2/DQ8 was successful in 697 and EuroArray-typing in 696 of 698 DNA samples. For the other 9 patients without central
Figure 1. Flow chart of eligible, recruited, and excluded patients and central diagnosis of final cohort ( $n=707$ ); for the nonbiopsy approach, local serology results have been considered. In total, 96 patients were excluded; of those, 36 due to nonevaluable histopathology and 60 for other reasons.

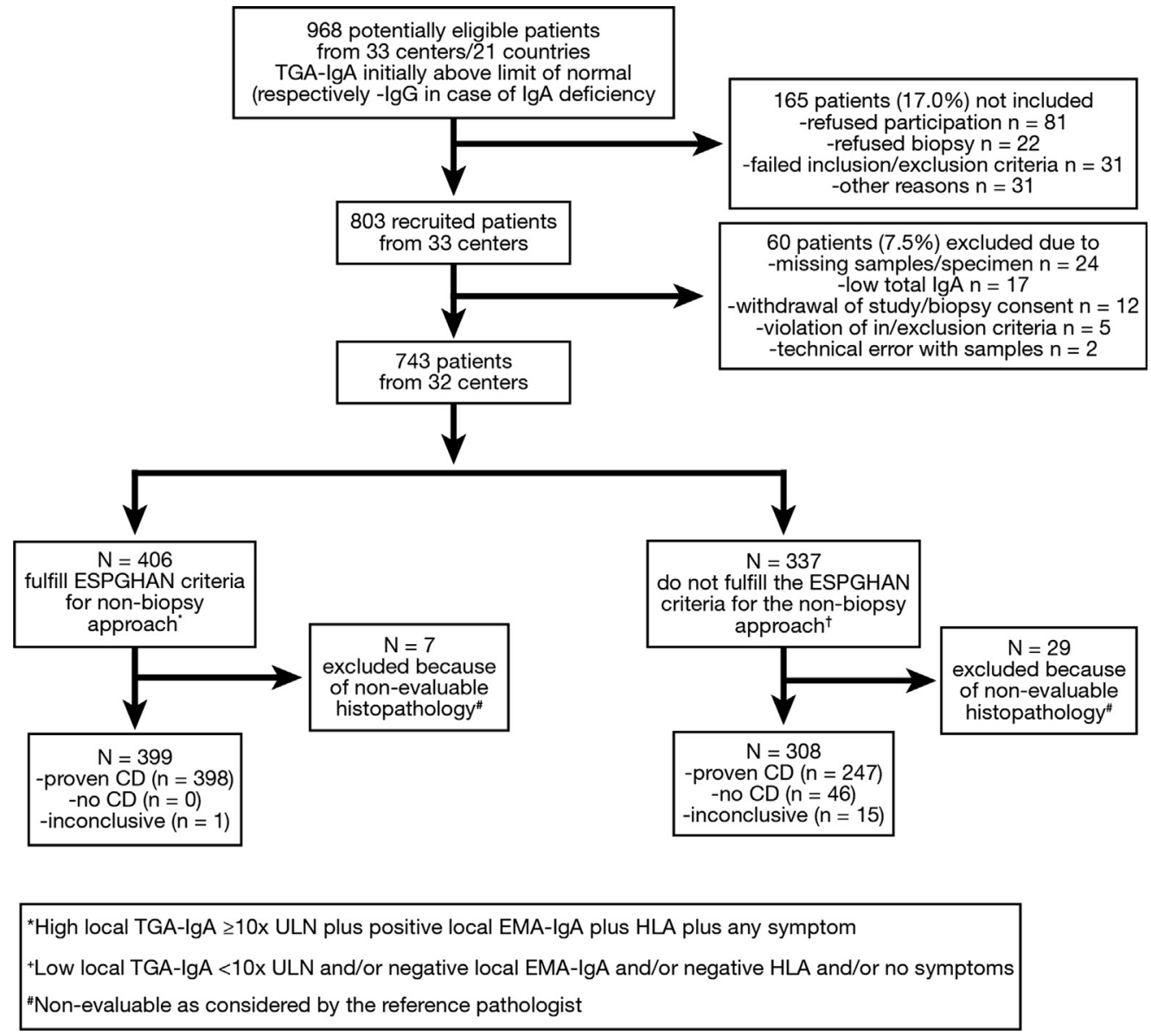


Table 1.General Characteristics of the Final Cohort $(n=707)$

\begin{tabular}{|c|c|c|c|c|c|}
\hline \multirow[b]{2}{*}{ Basic characteristics } & \multicolumn{3}{|c|}{ Patients by clinical manifestation } & \multicolumn{2}{|r|}{ Total } \\
\hline & $\begin{array}{c}\text { Malabsorption } \\
\text { symptom(s) }^{a} \\
\mathrm{n}=384-405^{b}\end{array}$ & 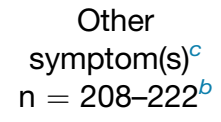 & $\begin{array}{c}\text { No } \\
\text { symptoms } \\
\mathrm{n}=76-80^{b}\end{array}$ & $\mathrm{n}$ & \\
\hline Age $(y)$ median (min;max) & $5.0(0.7 ; 18.0)$ & $7.6(1.1 ; 18.5)$ & $8.4(2.4 ; 18.6)$ & 707 & $6.2(0.7 ; 18.6)$ \\
\hline Female (\%) & 61.2 & 72.1 & 65.0 & 707 & 65.1 \\
\hline Risk factors of CD (\%) & & & & & $\%$ \\
\hline 1st degree relative & 13.0 & 14.5 & 53.2 & 693 & 18.0 \\
\hline 2nd degree relative & 7.6 & 11.1 & 9.2 & 668 & 8.8 \\
\hline T1DM & 4.7 & 12.6 & 22.5 & 705 & 9.2 \\
\hline Autoimmune thyroiditis & 1.3 & 4.2 & 2.5 & 690 & 2.3 \\
\hline Down syndrome & 1.5 & 0.0 & 2.5 & 705 & 1.1 \\
\hline Turner syndrome & 0.0 & 0.4 & 1.3 & 707 & 0.3 \\
\hline Gluten consumption (\%) & & & & & $\%$ \\
\hline Daily & 95.2 & 92.3 & 94.9 & 677 & 94.2 \\
\hline$\geq 3$ to 4 times/wk & 4.1 & 6.8 & 3.8 & 677 & 4.9 \\
\hline 1 to 2 times/wk & 0.8 & 1.0 & 1.3 & 677 & 0.9 \\
\hline Basic laboratory parameters (\%) & & & & & $\%$ \\
\hline Hemoglobin $<$ reference for age & 28.6 & 0.0 & 0.0 & 686 & 16.5 \\
\hline Albumin $<$ reference for age & 10.0 & 5.8 & 2.0 & 531 & 7.9 \\
\hline Alanine aminotransferase $>$ reference for age & 9.8 & 5.5 & 7.0 & 613 & 8.2 \\
\hline Thyroid peroxidase $>$ reference for age & 12.0 & 13.4 & 5.6 & 160 & 11.9 \\
\hline HLA risk group ${ }^{d, e}$ & & & & & $\%$ \\
\hline 1 & 32.4 & 23.4 & 27.5 & 205 & 29.0 \\
\hline 2 & 8.6 & 10.4 & 2.5 & 60 & 8.5 \\
\hline 3 & 44.2 & 45.9 & 42.5 & 315 & 44.5 \\
\hline 4 & 6.2 & 4.1 & 6.3 & 39 & 5.5 \\
\hline $5^{f}$ & 8.6 & 16.2 & 21.2 & 88 & 12.5 \\
\hline
\end{tabular}

\footnotetext{
${ }^{a}$ Malabsorption symptoms: diarrhea, weight loss or insufficient weight gain, growth failure, iron-deficiency anemia.

${ }^{b} \mathrm{~N}$ of patients for whom data are available vary between the different listed characteristics.

${ }^{\circ}$ Other clinical signs and symptoms: abdominal pain, constipation, abdominal distention, flatulence, vomiting, anorexia, fatigue, irritability/moodiness, lack of concentration, and in children $>12 \mathrm{y}$ : delayed puberty, amenorrhea.

${ }^{d} \mathrm{HLA}$ risk groups were defined as follows: group 1 is associated with the highest risk and included DR3-DQ2/DR3-DQ2 (DQ2.5/DQ2.5) and DR3-DQ2/DR7-DQ2 (DQ2.5/DQ2.2); group 2 DR7-DQ2/DR5-DQ7 (DQ2.2/DQ7); group 3 DR3-DQ2/DR5DQ7 (DQ2.5/DQ7), DR3-DQ2/DR4-DQ8 (DQ2.5/DQ8), and DR3-DQ2/other (DQ2.5/other); group 4 DR7-DQ2/DR7-DQ2 (DQ2.2/DQ2.2), DR7-DQ2/DR4-DQ8 (DQ2.2/DQ8), and DR4-DQ8/DR4-DQ8 (DQ8/DQ8); and group 5, which is associated with a very low or no risk for CD includes DR7-DQ2/other (DQ2.2/other), DR4-DQ8/DR5-DQ7 (DQ8/DQ7), and DR4-DQ8/other (DQ8/other); "other" refers to any HLA-DQ haplotype except DR3-DQ2, DR7-DQ2, DR4-DQ8, or DR5-DQ7.

${ }^{e}$ Based on results from Eu-Gen-typing (Eurospital) for 697 patients, on EUROarray (Euroimmun) for 1 patient and for local HLA typing results for 9 patients.

Thereof in 16 patients none of the CD-related risk alleles or only alleles encoding the $\alpha$-subunit (without the corresponding $\beta$-subunit) of DQ2 and/or DQ8 were present and were therefore regarded as HLA-DQ2/DQ8 negative.
}

DNA sample, local HLA-typing was available and considered for analysis. In total, 18 of 707 patients were HLA-DQ2/DQ8 negative. For 2 of 18 patients with high suspicion of $C D$, the third typing with new DNA material was HLA-D2/DQ8 positive; the remaining 16 patients had no CD (Supplementary Table 10).

Central diagnosis in the final cohort $(n=707)$ was proven CD in 645 (91.2\%), no CD in 46 (6.5\%), and inconclusive case in 16 (2.3\%) patients (Supplementary Table 11).

Sixty-four patients had tentatively started a gluten-free diet before the diagnostic workup of CD; 32 of those within 12 months before biopsy. All of them had a clear diagnosis of CD. None of the inconclusive patients had been on a gluten-free diet before.

\section{Diagnostic Accuracy in Clinical Practice}

Using the central diagnosis as reference, the diagnostic accuracies of local TGA-IgA $\geq 10 x U L N$ in combination with other criteria (scenarios) are shown in Table 2. Considering all 16 inconclusive cases as no $\mathrm{CD}$, high local TGA-IgA as a single criterion (scenario 1) revealed 4 falsepositive patients $(0.56 \%), 2$ of them had T1DM. If EMA-IgA was included (scenario 4), 2 false-positive patients remained $(0.28 \%)$. HLA results did not improve accuracies (scenario 4).

If all ESPGHAN criteria for the nonbiopsy approach were fulfilled (Table 2, scenario 5, 56.4\% of the cohort), 1 patient with unspecific symptoms remained false positive. If only malabsorption symptoms would qualify $339.3 \%$ of the patients, scenario 6), the PPV increased to $100 \%$. 
Table 2. Diagnostic Accuracies With 95\% Cls to Diagnose CD Based on Local TGA-IgA Tests in Combination With Other Criteria, Either Considering Inconclusive Cases as No CD (Scenarios 1-6, $\mathrm{n}=707$ ) or Excluding Inconclusive Cases (Scenarios 7-12, $\mathrm{n}=691$ )

\begin{tabular}{|c|c|c|c|c|c|c|c|c|c|c|}
\hline Scenario & $\mathrm{n}$ & Combination & TP & FP & FN & TN & $\begin{array}{l}\text { Sensitivity }^{a} \\
{[95 \% \mathrm{Cl}]}\end{array}$ & $\begin{array}{l}\text { Specificity } \\
{[95 \% \mathrm{Cl}]}\end{array}$ & $\begin{array}{c}\text { PPV } \\
{[95 \% \mathrm{Cl}]}\end{array}$ & $\begin{array}{c}\mathrm{LR}+ \\
{[95 \% \mathrm{Cl}]}\end{array}$ \\
\hline 1 & 707 & Local TGA $\geq 10 x U L N$ & 458 & 4 & 187 & 58 & $71.01[67.34 ; 74.48]$ & 93.548 [84.30; 98.21] & 99.134 [97.80; 99.76] & $11.01[4.26 ; 28.43]$ \\
\hline 2 & 707 & + any symptom(s) & 408 & 3 & 237 & 59 & $63.26[59.40 ; 66.99]$ & $95.161[86.50 ; 98.99]$ & $99.270[97.88 ; 99.85]$ & $13.07[4.33 ; 39.49]$ \\
\hline 3 & 707 & + malabsorption $^{b}$ & 286 & 1 & 359 & 61 & 44.34 [40.46; 48.27] & 98.387 [91.34; 99.96] & 99.652 [98.07; 99.99] & $27.49[3.93 ; 192.50]$ \\
\hline 4 & 707 & $\begin{array}{l}\text { Local TGA } \geq 10 x U L N \\
+ \text { EMA }^{c}\left(+/-\mathrm{HLA}^{\alpha}\right)\end{array}$ & 447 & 2 & 198 & 60 & $69.30[65.58 ; 72.84]$ & $96.774[88.83 ; 99.61]$ & 99.555 [98.40; 99.95] & $21.48[5.49 ; 84.07]$ \\
\hline 5 & 707 & + any symptom(s) & 398 & 1 & 247 & 61 & $61.71[57.83 ; 65.47]$ & 98.387 [91.34; 99.96] & 99.749 [98.61; 99.99] & $38.26[5.47 ; 267.60]$ \\
\hline 6 & 707 & + malabsorption $^{b}$ & 278 & 0 & 367 & 62 & $43.10[39.24 ; 47.02]$ & $100.0[94.22 ; 100.00]$ & $100.00[98.68 ; 100.00]$ & $\infty$ \\
\hline \multicolumn{11}{|c|}{ Excluding all inconclusive cases } \\
\hline 7 & 691 & Local TGA $\geq 10 x U L N$ & 458 & 1 & 187 & 45 & 71.01 [67.34; 74.48] & 97.826 [88.47; 99.95] & 99.782 [98.79; 99.99] & $32.66[4.70 ; 227.10]$ \\
\hline 8 & 691 & + any symptom(s) & 408 & 1 & 237 & 45 & $63.26[59.40 ; 66.99]$ & 97.826 [88.47; 99.95] & 99.756 [98.65; 99.99] & $29.10[4.18 ; 202.40]$ \\
\hline 9 & 691 & + malabsorption $^{b}$ & 286 & 0 & 359 & 46 & 44.34 [40.46; 48.27] & $100.00[92.29 ; 100.00]$ & $100.00[98.72 ; 100.00]$ & $\infty$ \\
\hline 10 & 691 & $\begin{array}{l}\text { Local TGA } \geq 10 x U L N \\
+\mathrm{EMA}^{c}\left(+/-\mathrm{HLA}^{d}\right)\end{array}$ & 447 & 0 & 198 & 46 & $69.30[65.58 ; 72.84]$ & $100.00[92.29 ; 100.00]$ & $100.00[99.18 ; 100.00]$ & $\infty$ \\
\hline 11 & 691 & + any symptom(s) & 398 & 0 & 247 & 46 & $61.71[57.83 ; 65.47]$ & $100.00[92.29 ; 100.00]$ & 100.00 [99.08; 100.00] & $\infty$ \\
\hline 12 & 691 & + malabsorption $^{b}$ & 278 & 0 & 367 & 46 & $43.10[39.24 ; 47.02]$ & $100.00[92.29 ; 100.00]$ & $100.00[98.68 ; 100.00]$ & $\infty$ \\
\hline
\end{tabular}

NOTE. Scenarios 5 and 11 correspond to the current ESPGHAN criteria for the nonbiopsy approach.

FN, false negative; FP, false positive; LR+, positive likelihood ratio; PPV, positive predictive value; TN, true negative; TP, true positive; $\infty$, infinity. a Sensitivity: proportion of patients qualifying for the nonbiopsy approach.

${ }^{b}$ Malabsorption symptoms comprise any of the following: diarrhea, weight loss or insufficient weight gain, growth retardation, iron deficiency anemia.

${ }^{\circ}$ EMA-IgA: results of local clinical centers were considered, except for 25 patients without local EMA-IgA result for whom the central EMA-lgA was used.

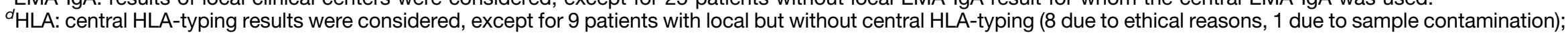
however, including HLA outcomes had no effect on the accuracies. 
In the subsample analysis excluding 16 inconclusive cases, 1 patient was false positive for TGA $\geq 10 x U L N$ (scenarios 7 and 8). If malabsorption and/or EMA-IgA were included in the diagnostic decision, no false positives were found (scenarios 9-12).

Details on false-positive patients are summarized in Supplementary Table 12.

\section{Diagnostic Accuracy of Central Serology Evaluations}

PPVs for each central TGA result $\geq 10 x$ ULN ( $\mathrm{n}=696$ to 707) ranged between $99.63(98.67 ; 99.96)$ and 100.00 (99.23; 100.00) (Figure 2). The prevalence of high TGA results varied between $22.64(19.46 ; 26.06)$ and 83.57 (80.48; 86.34) (Supplementary Table 13). Tests T4 and T6 did not reach a PPV of $\geq 99 \%$ for the lower bound of the 95\% CI due to respectively 1 and 2 additional false-positive patients; of those, there was 1 child with T1DM. If malabsorption symptoms were considered for the decision, or if inconclusive cases were excluded, no false positive was found.

For the DGP-IgGs $\geq 10 x U L N$, the specificity was high (1 false positive) but sensitivity was low (for details, see Supplementary Table 14 and Supplementary Figure 3).

\section{Discussion}

The results of our prospective multicenter diagnostic evaluation study ProCeDE show that the ESPGHAN nonbiopsy approach allows a correct diagnosis of CD. At least $50 \%$ of affected children in clinical practice will benefit from this nonbiopsy approach, which reduces burden and risks of endoscopy and anesthesia while saving costs for health care systems. ${ }^{13}$ This ensuring conclusion was achieved in spite of using local results of a large variety of different TGA and EMA tests, which were performed in many laboratories in very different settings and countries.
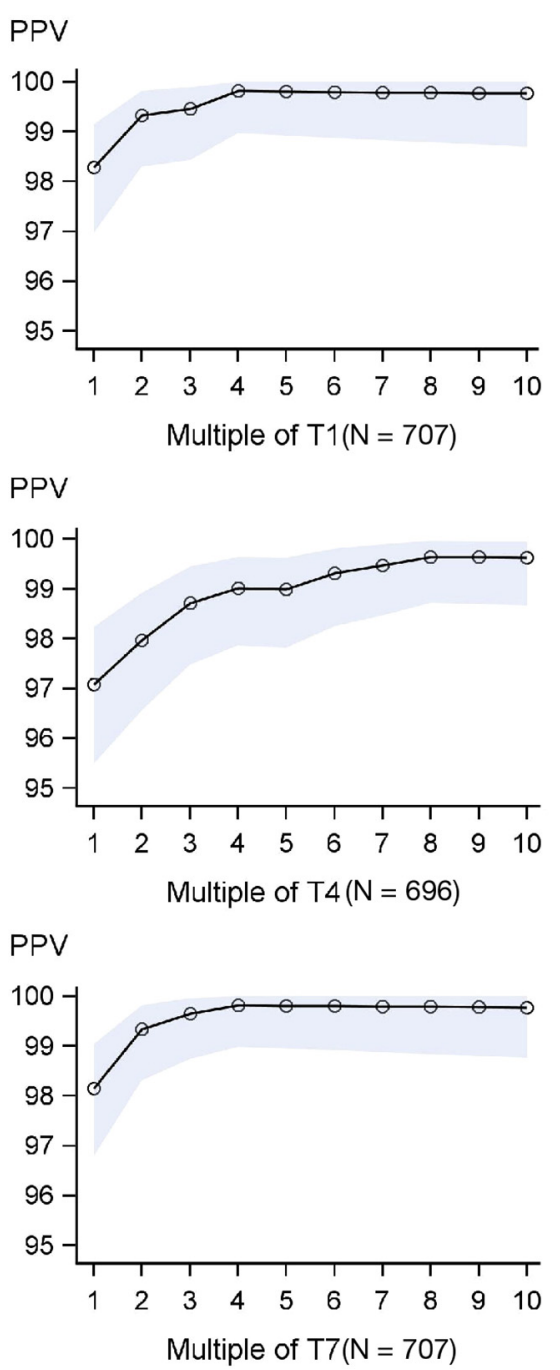

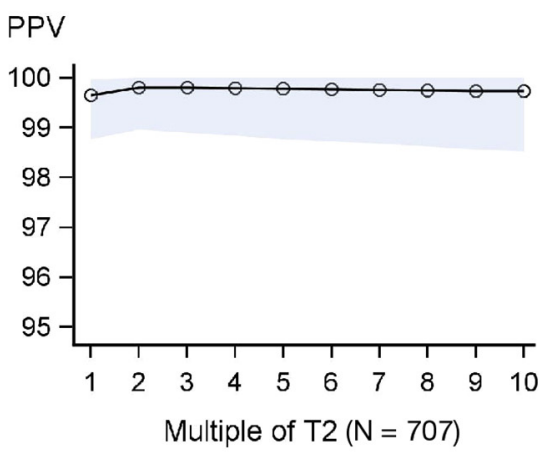

PPV
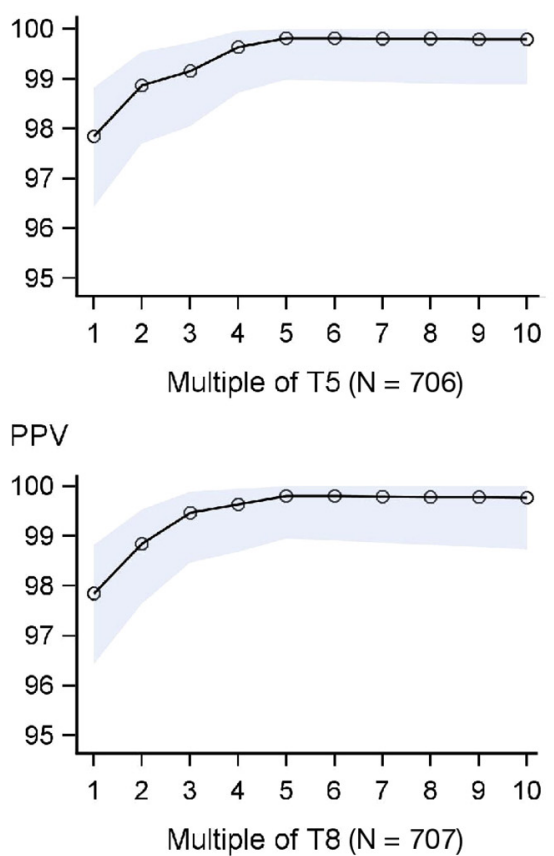

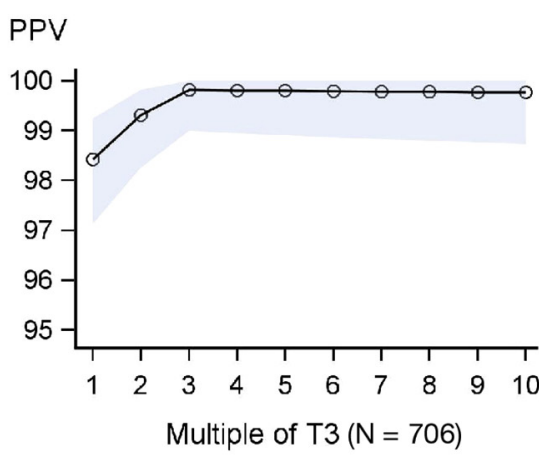

PPV

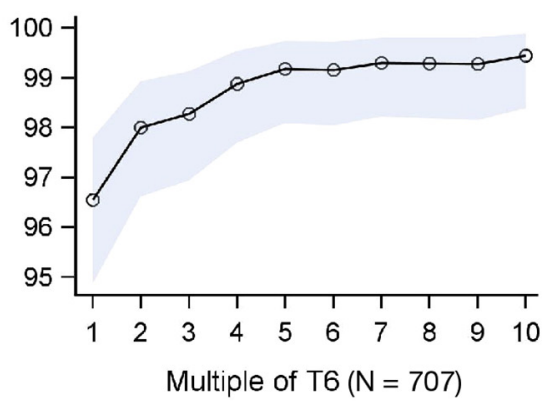

PPV

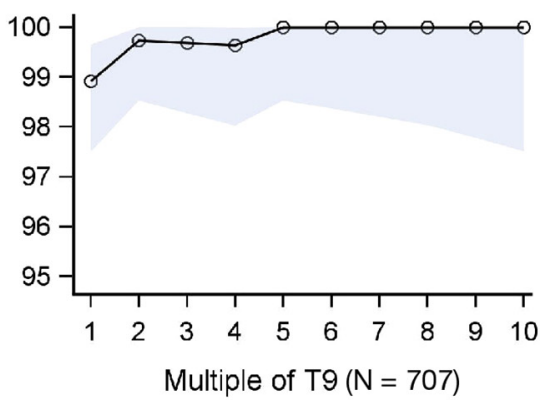

Figure 2. $P P V$ with $95 \% \mathrm{Cl}$ (gray shaded) for $\mathrm{CD}$ diagnosis for each central TGA-serology, including 8 TGA-IgA tests (T1 to T8) and 1 TGA-lgG test (T9), all with calibration curve-based result calculations. The $x$-axis shows the multiple of the respective limit of normal according to the manufacturer's instructions (all truncated at 10xULN), the $y$-axis shows the PPV. Please see Table 3 for the names and manufacturers of each test. 
Table 3.Specifications of Central Serology Tests

\begin{tabular}{|c|c|c|c|c|c|c|c|}
\hline $\begin{array}{l}\text { Test } \\
\text { no. }\end{array}$ & $\begin{array}{l}\text { Trade } \\
\text { name }\end{array}$ & Manufacturer & $\begin{array}{l}\text { Type of } \\
\text { analysis }\end{array}$ & Machine & $\begin{array}{l}\text { Limit of } \\
\text { normal }\end{array}$ & $\begin{array}{l}\text { Limit of } \\
\text { normal (upper, } \\
\text { if any range) }\end{array}$ & $\begin{array}{l}\text { Performing } \\
\text { laboratory }\end{array}$ \\
\hline \multicolumn{8}{|c|}{ EMA-test } \\
\hline E1 & $\begin{array}{l}\text { Anti-Endomysium-IIFT IgA (or IgG) } \\
\text { Tissue: monkey esophagus and liver }\end{array}$ & EUROIMMUN & Immunofluorescence & $\begin{array}{l}\text { Fluorescence microscope } \\
\text { Zeiss }\end{array}$ & $1: 2.5^{a}$ & $1: 5$ & Munich $^{b}$ \\
\hline \multicolumn{8}{|c|}{ TGA-tests } \\
\hline T1 & EliA Celikey $\lg A$ & Thermo Fisher & $\begin{array}{l}\text { Fluoescence Enzyme } \\
\text { Immunoassay }\end{array}$ & Phadia 250 & $7 \mathrm{U} / \mathrm{mL}$ & $10 \mathrm{U} / \mathrm{mL}$ & Odense \\
\hline T2 & VarelisA Celikey tTG-IgA ELISA & Thermo Fisher & ELISA & EUROIMMUN Analyzer I & $5 \mathrm{U} / \mathrm{mL}$ & $8 \mathrm{U} / \mathrm{mL}$ & Odense \\
\hline T3 & QUANTA Lite tTG IgA & Inova Diagnostics & ELISA & EUROIMMUN Analyzer I & $4 \mathrm{U} / \mathrm{mL}$ & $10 \mathrm{U} / \mathrm{mL}$ & Odense \\
\hline T4 & QUANTA Flash tTG IgA & Inova Diagnostics & Chemiluminescence & BioFlash & $20 \mathrm{U}$ & $30 \mathrm{U}$ & Munich \\
\hline T5 & Eu-tTG IgA New - code 9105 & Eurospital & ELISA & EUROIMMUN Analyzer I & $9 \mathrm{U} / \mathrm{mL}$ & $16 \mathrm{U} / \mathrm{mL}$ & Odense \\
\hline T6 & Anti-Gewebstransglutaminase-ELISA (IgA) & EUROIMMUN & ELISA & EUROIMMUN Analyzer I & $20 \mathrm{RU} / \mathrm{mL}$ & - & Odense \\
\hline T7 & Anti-TG2-IgA (open form) & R-Biopharm/Zedira & ELISA & EUROIMMUN Analyzer I & $2.6 \mathrm{U} / \mathrm{mL}$ & $3.5 \mathrm{U} / \mathrm{mL}$ & Odense \\
\hline T8 & Anti-TG2-IgA (closed form/standard) & R-Biopharm/Zedira & ELISA & EUROIMMUN Analyzer I & $2.6 \mathrm{U} / \mathrm{mL}$ & $3.5 \mathrm{U} / \mathrm{mL}$ & Odense \\
\hline T9 & Anti-TG2-IgG (open form) & R-Biopharm/Zedira & ELISA & EUROIMMUN Analyzer I & $2.6 \mathrm{U} / \mathrm{mL}$ & $3.5 \mathrm{U} / \mathrm{mL}$ & Odense \\
\hline \multicolumn{8}{|c|}{ DGP-tests } \\
\hline D1 & EliA GliadinDP IgG & Thermo Fisher & $\begin{array}{l}\text { Fluorescence Enzyme } \\
\text { Immunoassay }\end{array}$ & Phadia 250 & $7 \mathrm{U} / \mathrm{mL}$ & $10 \mathrm{U} / \mathrm{mL}$ & Odense \\
\hline D2 & QUANTA Lite DGP IgG & Inova Diagnostics & ELISA & EUROIMMUN Analyzer I & $20-30 \mathrm{U}$ & $30 \mathrm{U}$ & Odense \\
\hline D3 & QUANTA Flash DGP IgG & Inova Diagnostics & Chemiluminescence & BioFlash & $20-30 \cup$ & $30 \mathrm{U}$ & Munich \\
\hline D4 & a-Gliapep-IgG - code 9138 & Eurospital & ELISA & EUROIMMUN Analyzer I & $10 \mathrm{U} / \mathrm{mL}$ & - & Odense \\
\hline D5 & Anti-Gliadin(GAF-3X)-ELISA IgG & EUROIMMUN & ELISA & EUROIMMUN Analyzer I & $25 \mathrm{RU} / \mathrm{mL}$ & - & Odense \\
\hline D6 & Anti-DGPx1-IgG & R-Biopharm/Zedira & ELISA & EUROIMMUN Analyzer I & $5.8 \mathrm{U} / \mathrm{mL}$ & $8.4 \mathrm{U} / \mathrm{mL}$ & Odense \\
\hline
\end{tabular}

ELISA, enzyme-linked immunosorbent assay.

$a_{1: 2.5}$ dilutions done in patients $(n=16)$ with negative central EMA at 1:5 due to with discrepant results or negative HLA.

${ }^{b}$ Immunofluorescence evaluations were exclusively done by one experienced bioanalyst.

${ }^{c}$ only done in IgA-deficient cases or if exclusion of IgA deficiency needed to be confirmed. 
Since the publication of the current ESPGHAN guidelines, several studies investigated if $C D$ can be correctly diagnosed without biopsies, both in children and adults. ${ }^{7,13-29}$ Most were of retrospective nature, done by single centers, applied only 1 or a few TGA tests, and used histopathology as the only reference standard for diagnosis. These studies had a high risk of selection bias, excluding inconclusive cases and not acknowledging the limited interpathology agreement. ${ }^{4-6,30}$ Our finding with discordance regarding CD diagnosis between local and central pathologists questions histopathology as a reference standard in validation studies and supports our approach to build the reference diagnosis on concordant results of different diagnostic tests. There are concerns regarding the concept of using the same threshold (10xULN) of nonstandardized tests with recognized interand intratest variability as criterion to omit biopsies for CD diagnosis. ${ }^{31}$ As this approach gives quantification of TGA concentrations a large weight, type and quality of serology tests are crucial and calibration curves allowing linear calculation of results are obligatory. ${ }^{1}$ In the ProCeDE study, 9 different TGA tests were centrally used; 7 of them reliably predicted CD with a PPV of $100 \%$ with titers $\geq 10 x$ ULN and at even lower levels. This raises the question to further lower the threshold. However, the central laboratory had one standardized system following all manufacturers' instructions, using the same calibration curves on automatized machines with fixed settings, involving the same laboratory technicians. In practice, interlaboratory variability is high, ${ }^{15,32}$ which we confirmed when comparing central and local results of the same manufacturer (Supplementary Figure 6; Supplementary Table 16). In our study, 10 different TGAIgA tests were used by the local laboratories of the 32 centers, with only 4 patients with high TGA-IgA levels $\geq 10 x U L N$ being false positive. This strongly supports that the current ESPGHAN criteria are robust in clinical practice. However, accounting for the inter- and intralaboratory variabilities and the lack of standardization among TGA-IgA tests and laboratories, ${ }^{15}$ we recommend against lowering this threshold and keeping the 10xULN as one criterion for the nonbiopsy approach.

Our data revealed that HLA-typing for DQ2/DQ8 does not improve accuracy of CD diagnosis without biopsies and can be omitted for this purpose. All patients with TGA-IgA $\geq 10 x U L N$ and positive EMA carried HLA-risk alleles. Only 2 of 645 patients with CD had initially a negative HLA status, both were later reliably identified as having initially falsenegative HLA results. Intertest agreement was close to perfect between the 2 HLA tests used (Supplementary Table 17). Negative results for HLA-DQ2/DQ8 in patients with TGA or EMA positivity are most likely false negative caused by mixing up blood samples or due to very rare risk allele combinations not recognized by the test systems. ${ }^{1,33,34}$

A positive EMA result as obligatory criterion for the nonbiopsy approach is still debated. EMA is more specific than TGA and DGP testing, ${ }^{35}$ but immunofluorescence requires an experienced examiner. ${ }^{36}$ As expected, sensitivity (proportion of patients qualifying for the nonbiopsy approach) varied between participating centers. In concordance with previous studies, ${ }^{18,19,21,37}$ inclusion of EMA improved the positive likelihood ratio and the PPV. Our results support the use of EMA as confirmatory test when $\mathrm{CD}$ is diagnosed without biopsies.

The ESPGHAN criteria also request the presence of symptoms for the nonbiopsy approach. Symptoms of malabsorption increase the pretest probability for $C D$ compared with less specific complaints, such as abdominal pain, and thereof the posttest probability of a given serological result. This is indicated by a higher PPV and positive LR, as shown in scenarios 1,2, and 3 (Table 2) ${ }^{16,17,21,23}$ Transient TGA-IgA positivity occurs in persons at genetic risk for CD, particularly those with T1DM, ${ }^{38}$ although TGA-IgA levels are mostly low. False-positive moderate or even high titer levels are more likely when serologic tests with a steeper calibration curve are applied (T4 and T6 in the central laboratory). A recent population-based screening study in Swedish schoolchildren suggested that the nonbiopsy approach is also safe to diagnose $\mathrm{CD}$ in the absence of symptoms. ${ }^{24}$ The number of 80 asymptomatic children in our study, particularly those with T1DM, was too low to draw valid conclusions.

There is some concern that the nonbiopsy approach may result in clinically relevant missed comorbidities, such as gastroesophageal reflux disease, eosinophilic esophagitis, or Helicobacter pylori infection-related complications. ${ }^{39}$ However, our data suggest that the frequency of pathologic findings unrelated to untreated CD is rare and most likely not higher than in the general population (Supplementary Results, Section 2.7).

The main strength of our study is the large prospective cohort recruited in a variety of clinical centers from different countries and settings, which truly reflects clinical practice. Further advantages comprise detailed assessment of medical history and clinical symptoms, the large panel of local and central laboratory tests, including central EMAIgA, 2 HLA-typing tests, and central reference pathology. In contrast to previous studies, we did not rely on local histopathology as the "gold standard," we based the diagnosis on concordant diagnostic test results and implemented a careful workup and review process of initially unclear cases including recuttings and a blinded morphometric analysis. Our study showed the complexity and pitfalls occurring in the diagnostic workup of children with suspected $C D$. We considered inconclusive cases as a separate group to transparently reflect that a clear diagnosis or exclusion of $\mathrm{CD}$ is not always possible.

As a limitation, not all eligible patients were recruited, most due to general concerns toward study participation $(\mathrm{n}=81)$. Eleven patients with initially positive TGA-IgA in external laboratories were retested for TGA-IgA before considering endoscopy and not confirmed to have autoimmunity and therefore not included. In only 22 patients, the reason for not being recruited was refusal toward biopsy, which may bear a risk for bias but does overall minimally influence the proportion of children qualifying for the nonbiopsy approach. Furthermore, some recruited children were excluded due to missing samples or data $(n=24)$ or insufficient quality of histology specimen $(\mathrm{n}=36)$. 
Reevaluation of initially inconclusive cases was possible only when paraffin blocks were available. As the main reasons for nonrecruiting or excluding patients seem to be random and independent from our main outcome, we consider a low risk for selection bias within our cohort.

We conclude from our results that the new ESPGHAN diagnostic criteria allowing omission of biopsies enables a correct diagnosis of CD in symptomatic children if TGA-IgA levels exceed 10xULN and positive EMA-IgA confirms celiac disease autoimmunity in a second blood sample. If one of these criteria is not fulfilled, biopsy should be performed to confirm the diagnosis. HLA-typing for DQ2/DQ8 does not contribute to the accuracy of this 2-step approach and therefore is not necessary in these children.

\section{Appendix}

Other members of the ProCeDE study group:

Piotr Socha, MD, PhD, Department of Gastroenterology, Hepatology, Nutritional Disorders and Pediatrics and Prof. Bozena Cukrowska, Pathology Department, Children's Memorial Health Institute, Warsaw, Poland; Hania Szajewska, $\mathrm{MD}, \mathrm{PhD}$, Pediatrics, Medical University of Warsaw and Jan Wyhowski, MD, Pathomorphology, Pediatric University Hospital, Warsaw, Poland; Nailah Brown and Gauri Batra, MD, Royal Manchester Children's Hospital, Manchester, UK; Zrinjka Misak, MD, PhD, the Referral Center for Pediatric Gastroenterology and Nutrition, Children's Hospital Zagreb, and Sven Seiwerth, MD, PhD, Institute of Pathology, Medical School University of Zagreb, Zagreb, Croatia; Yulia Dmitrieva, MD, PhD, and Dmitry Abramov, MD, FSCC PHOI, Russian Medical Academy of Continuing Postgraduate Education; Yvan Vandenplas, MD, PhD, and Annieta Goossens, MD, PhD, Pathology, Kidz Health Castle, UZ Brussels, Brussels, Belgium; Maaike W. Schaart, MD, PhD, Pediatrics, and V.T.H.B.M. Smit, MD, PhD, Pathology, Leiden University Medical Center (LUMC); Nicolas Kalach, MD, PhD, and Pierre Gosset, MD, PhD, Hôpital Saint Vincent de Paul, Catholic University; Judit B. Kovács, MD, PhD and Anikó Nagy, MD, Gastroenterology and Nephrology, Ilona Lellei MD, and Rita Kőbányai MD, Pathology, Heim Pál Children's Hospital, Budapest; Katayoun Khatami, MD, PhD, Department of Pediatric Gastroenterology, Hepatology and Nutrition, Mofid children hospital, Shahid Beheshti University of Medical Sciences, Tehran, Iran, Shahid Beheshti University of Medical Sciences, and Maryam Monajemzadeh, MD, PhD, Pathology Unit, Children's Medical Center Hospital Tehran; Konstantina Dimakou, MD, Division of Gastroenterology and Hepatology, First Department of Pediatrics, and Amalia Patereli, MD, Children's Hospital «Agia Sofia», University of Athens; Tine Plato Hansen, MD, Clinical Pathology, Odense University Hospital; Rajko Kavalar, MD, PhD, Department of Pathology, University Medical Center Maribor, Maribor, Slovenia; Miguel Bolonio, Pediatric Gastroenterology and Hepatology and David Ramos, Pathology Unit, La Fe University Hospital Valencia; Hubert Kogler, MD, St. Anna Children's Hospital, Gabriele Amann, MD, Department of Pathology, Medical University Vienna; Roberta Kosova, MD, and Mariantonia Maglio, PhD, Department of Translational
Medical Sciences and European Laboratory for the Investigation of Food-Induced Diseases, University Federico II, Naples Italy; Elke Janssens, MD, Pediatrics, and Ruth Achten, MD, Pathology, Jessa Hospital, Hasselt; Pavel Frühauf, MD, PhD, Pediatrics and Adolescent Medicine, and Helena Skálová, MD, pathologist, Institute of Pathology, First Faculty of Medicine and General University Hospital, Charles University, Prague, Czech Republic; Thomas Kirchner, MD, PhD, Institute of Pathology, Ludwig Maximilian's University Munich, Munich, Germany; Laura Petrarca, MD, Pediatrics and Infantile Neuropsychiatry, and Fabio Massimo Magliocca, MD, Radiology, Oncology and Human Pathology, "Sapienza" University, Rome, Italy; Francesc Martínez, MD, Gastroenterology Unit and Vanesa Morente, PhD, Pathology Unit, Hospital Universitari de Sant Joan de Reus, IISPV, URV; Sonja Thanner-Lechner, MSc, Pediatrics, and Manfred Ratschek, MD, Institute for Pathology, Medical University of Graz, Austria; Marco Gasparetto, MD, Pediatric Gastroenterology, Hepatology and Nutrition, and Liz Hook, MD, Pathology, Cambridge University NHS Foundation Trust, Addenbrookes Hospital, Cambridge, UK; Danielle Canioni, MD, Anatomo-Pathology, Hôpital Necker-Enfants Malades, Paris, France; Catherine Wanty, MD, Pediatric Gastroenterology and Anne Mourin, MD, Pathology Unit, Université Catholique de Louvain, Cliniques universitaires Saint Luc, Brussels, Belgium; Kaija Laurila, MSc, and Martine Vornane, MD, Centre for Child Health Research, University of Tampere and Tampere University Hospital, Tampere, Finland; Vered Nachmias Friedler, MD, Institute of Gastroenterology, Nutrition and Liver Diseases, Schneider Children's Medical Center and Sara L. Morgenstern, MD, Department of Pathology, Rabin Medical Center, Sackler Faculty of Medicine, Tel Aviv University, Israel; Jorge Amil Dias, MD, and Fátima Carneiro, MD, PhD, Hospital S. João, Porto, Portugal; Stephanie Van Biervliet, MD, PhD, and Saskia Vande Velde, Department of Pediatric Gastroenterology, Hepatology and Nutrition, Ghent University Hospital, Gent, Belgium; Hany Banoub, MD, Queen Mary's Hospital for Children, and Steve Sampson, Department of Pathology, Epsom and St Helier University NHS Trust, Carshalton, UK; Annette M. Müller, MD, PhD, Department of Pathology, University of Bonn, Bonn, Germany; Adina Ene, MD, Histology Department National Institute for Mother and Child Health, Bucharest, Romania; Mandana Rafeey, MD, PhD, Liver and Gastrointestinal Research Center and Amir Taher Eftekhar Sadat, MD, PhD, Pathology Unit, Tabriz University of Medical Sciences, Tabriz, Iran.

\section{Supplementary Material}

Note: To access the supplementary material accompanying this article, visit the online version of Gastroenterology at www.gastrojournal.org, and at http://dx.doi.org/10.1053/ j.gastro.2017.06.002.

\section{References}

1. Husby S, Koletzko S, Korponay-Szabo IR, et al. European Society for Pediatric Gastroenterology, 
Hepatology, and Nutrition guidelines for the diagnosis of coeliac disease. J Pediatr Gastroenterol Nutr 2012; 54:136-160.

2. Rewers M. Epidemiology of celiac disease: what are the prevalence, incidence, and progression of celiac disease? Gastroenterology 2005;128:S47-S51.

3. Salardi S, Volta U, Zucchini S, et al. Prevalence of celiac disease in children with type 1 diabetes mellitus increased in the mid-1990s: an 18-year longitudinal study based on anti-endomysial antibodies. J Pediatr Gastroenterol Nutr 2008;46:612-614.

4. Arguelles-Grande C, Tennyson CA, Lewis SK, et al. Variability in small bowel histopathology reporting between different pathology practice settings: impact on the diagnosis of coeliac disease. J Clin Pathol 2012; 65:242-247.

5. Mubarak A, Nikkels P, Houwen R, et al. Reproducibility of the histological diagnosis of celiac disease. Scand J Gastroenterol 2011;46:1065-1073.

6. Picarelli A, Borghini R, Donato G, et al. Weaknesses of histological analysis in celiac disease diagnosis: new possible scenarios. Scand J Gastroenterol 2014; 49:1318-1324.

7. Alessio MG, Tonutti E, Brusca I, et al. Correlation between IgA tissue transglutaminase antibody ratio and histological finding in celiac disease. J Pediatr Gastroenterol Nutr 2012;55:44-49.

8. Marsh M. Gluten, major histocompatibility complex, and the small intestine. A molecular and immunobiologic approach to the spectrum of gluten sensitivity. Gastroenterology 1992;102:330-354.

9. Oberhuber G, Granditsch G, Vogelsang H. The histopathology of coeliac disease: time for a standardized report scheme for pathologists. Eur J Gastroenterol Hepatol 1999;11:1185-1194.

10. Bourgey M, Calcagno G, Tinto N, et al. HLA related genetic risk for coeliac disease. Gut 2007;56:1054-1059.

11. Margaritte-Jeannin $\mathrm{P}$, Babron $\mathrm{MC}$, Bourgey $\mathrm{M}$, et al. $H L A-D Q$ relative risks for coeliac disease in European populations: a study of the European Genetics Cluster on Coeliac Disease. Tissue Antigens 2004;63: 562-567.

12. Korponay-Szabo IR, Troncone R, Discepolo V. Adaptive diagnosis of coeliac disease. Best Pract Res Clin Gastroenterol 2015;29:381-398.

13. Tortora R, Imperatore N, Capone P, et al. The presence of anti-endomysial antibodies and the level of anti-tissue transglutaminases can be used to diagnose adult coeliac disease without duodenal biopsy. Aliment Pharmacol Ther 2014;40:1223-1229.

14. Barker CC, Mitton C, Jevon G, Mock T. Can tissue transglutaminase antibody titers replace small-bowel biopsy to diagnose celiac disease in select pediatric populations? Pediatrics 2005;115:1341-1346.

15. Beltran L, Koenig M, Egner W, et al. High-titre circulating tissue transglutaminase-2 antibodies predict small bowel villous atrophy, but decision cut-off limits must be locally validated. Clin Exp Immunol 2014; 176:190-198.
16. Di Tola M, Marino M, Goetze S, et al. Identification of a serum transglutaminase threshold value for the noninvasive diagnosis of symptomatic adult celiac disease patients: a retrospective study. J Gastroenterol 2016; 51:1-9.

17. Donat E, Ramos JM, Sánchez-Valverde F, et al. ESPGHAN 2012 guidelines for coeliac disease diagnosis: validation through a retrospective Spanish multicentric study. J Pediatr Gastroenterol Nutr 2016; 62:284-291.

18. Gidrewicz D, Potter K, Trevenen CL, et al. Evaluation of the ESPGHAN Celiac Guidelines in a North American pediatric population. Am J Gastroenterol 2015;110: 760-767.

19. Klapp G, Masip E, Bolonio M, et al. Celiac disease: the new proposed ESPGHAN diagnostic criteria do work well in a selected population. J Pediatr Gastroenterol Nutr 2013;56:251-256.

20. Mubarak A, Wolters VM, Gerritsen SA, et al. A biopsy is not always necessary to diagnose celiac disease. J Pediatr Gastroenterol Nutr 2011;52:554-557.

21. Nevoral J, Kotalova R, Hradsky O, et al. Symptom positivity is essential for omitting biopsy in children with suspected celiac disease according to the new ESPGHAN guidelines. Eur J Pediatr 2014;173:497-502.

22. Trovato CM, Montuori M, Anania C, et al. Are ESPGHAN biopsy-sparing guidelines for celiac disease also suitable for asymptomatic patients. Am J Gastroenterol 2015; 110:1485-1489.

23. Vermeersch $P$, Geboes K, Mariën G, et al. Defining thresholds of antibody levels improves diagnosis of celiac disease. Clin Gastroenterol Hepatol 2013;11: 398-403.

24. Webb C, Norström F, Myléus A, et al. Celiac disease can be predicted by high levels of anti-tissue transglutaminase antibodies in population-based screening. J Pediatr Gastroenterol Nutr 2015;60:787-791.

25. Wolf J, Hasenclever D, Petroff D, et al. Antibodies in the diagnosis of coeliac disease: a biopsy-controlled, international, multicentre study of 376 children with coeliac disease and 695 controls. PLoS One 2014; 9:e97853.

26. Kurppa K, Salminiemi J, Ukkola A, et al. Utility of the new ESPGHAN criteria for the diagnosis of celiac disease in at-risk groups. J Pediatr Gastroenterol Nutr 2012; 54:387-391.

27. Elitsur $Y$, Sigman T, Watkins R, et al. Tissue transglutaminase levels are not sufficient to diagnose celiac disease in north american practices without intestinal biopsies. Dig Dis Sci 2017;62:175-179.

28. Smarrazzo A, Misak Z, Costa S, et al. Diagnosis of celiac disease and applicability of ESPGHAN guidelines in Mediterranean countries: a real life prospective study. BMC Gastroenterol 2017;17:17.

29. Fernández-Bañares F, Alsina M, Modolell I, et al. Are positive serum-IgA-tissue-transglutaminase antibodies enough to diagnose coeliac disease without a small bowel biopsy? Post-test probability of coeliac disease. J Crohns Colitis 2012;6:861-866. 
30. Webb C, Halvarsson B, Norström F, et al. Accuracy in celiac disease diagnostics by controlling the small-bowel biopsy process. J Pediatr Gastroenterol Nutr 2011; 52:549-553.

31. Egner W, Shrimpton A, Sargur R, et al. ESPGHAN Guidance on coeliac disease 2012: multiples of the upper limit of normal for decision making do not harmonise assay performance across centres. J Pediatr Gastroenterol Nutr 2012;55:733-735.

32. Li M, Yu L, Tiberti C, et al. A report on the International Transglutaminase Autoantibody Workshop for Celiac Disease. Am J Gastroenterol 2009;104:154-163.

33. Björck S, Lynch K, Brundin C, et al. Repeated screening can be restricted to at-genetic-risk birth cohorts. J Pediatr Gastroenterol Nutr 2016;62:271-275.

34. Bodd M, Tollefsen S, Bergseng E, et al. Evidence that HLA-DQ9 confers risk to celiac disease by presence of DQ9-restricted gluten-specific T cells. Hum Immunol 2012;73:376-381.

35. Giersiepen K, Lelgemann M, Stuhldreher N, et al. Accuracy of diagnostic antibody tests for coeliac disease in children: summary of an evidence report. J Pediatr Gastroenterol Nutr 2012;54:229-241.

36. Lewis NR, Scott BB. Systematic review: the use of serology to exclude or diagnose coeliac disease (a comparison of the endomysial and tissue transglutaminase antibody tests). Aliment Pharmacol Ther 2006;24:47-54.

37. Swallow K, Wild G, Sargur R, et al. Quality not quantity for transglutaminase antibody 2: the performance of an endomysial and tissue transglutaminase test in screening coeliac disease remains stable over time. Clin Exp Immunol 2013;171:100-106.

38. Simell S, Hoppu S, Hekkala A, et al. Fate of five celiac disease-associated antibodies during normal diet in genetically at-risk children observed from birth in a natural history study. Am J Gastroenterol 2007;102: 2016-2035.

39. Guandalini S, Newland C. Can we really skip the biopsy in diagnosing symptomatic children with celiac disease. J Pediatr Gastroenterol Nutr 2013;57:e24.

Received March 10, 2017. Accepted June 8, 2017.

\section{Reprint requests}

Address requests for reprints to: Sibylle Koletzko, MD, PhD, Dr. von Hauner Children's Hospital, Department of Pediatrics, University Hospital, LMU Munich Lindwurmstr. 4, 80337 Munich, Germany. e-mail: sibylle.koletzko@med.uni-muenchen.de; fax: +49-(0)89-44005-7898.

\section{Acknowledgments}

We thank ESPGHAN; AOK Bayern; Celiac Society of the United Kingdom "Coeliac UK"; Danish Celiac Society "Dansk Cøliakiforening"; Dutch Celiac Society "Nederlandse Coeliakie Vereniging"; Finnish Celiac Society
"Keliakialiitto"; German Celiac Society "Deutsche Zöliakie Gesellschaft"; Hungarian Celiac Society "Liszterzekenyek Erdekkepviseletenek Orszagos Egyesulete"; Italian Celiac Society "Associazione Italiana Celiachia" EUROIMMUN Medizinische Labordiagnostika AG (Lübeck, Germany); Eurospital SpA (Trieste, Italy); INOVA Diagnostics (USA), PhadiaThermoFisher (Sweden/USA), R-Biopharm/Zedira (Darmstadt, Germany) and Dr. Schär Germany for financial support.

We thank Wolfgang Lohr for the setup of the database and to Helmholtz Center Munich for storage of database on their server; Daniela Aust for second reference pathology; Lis Rasmussen, Birgit Jørgenson, and Line Sørensen Greve for central serology analysis; Erika Zilahi, University of Debrecen, for single nucleotide polymorphism typing of HLA-risk alleles; Viktória Vass, MD, Department of Pathology, Heim Pál Children's Hospital, Budapest, for support with recutting and scanning biopsy specimens for morphometry; Torben Barington, MD, DMSc, Clinical Immunology \& The OPEN Facility, Odense University Hospital for storing the serum samples in their biobank; and the BioBanc IISPV (B.0000853 + B.0000854) integrated in the Spanish National Biobanks Platform (PT13/0010/0029 \& PT13/0010/0062).

We thank the following study coordinators for support in collecting data and samples: Hossein Alimadadi, MD, PhD, Children Medical Center Hospital Tehran; Albina Innerhofer, MD, Karin Hammer, MD, Eva Pliemitscher, MD, Andrea Bruckdorfer, Birgit Jilka, St. Anna Children's Hospital, Medical University Vienna; Miroslav Hind'oš, Ing., Institute of Medical Biochemistry and Laboratory Diagnostics, First Faculty of Medicine \& General University Hospital, Charles University, Prague; Evgenija Homsak, Immunological Diagnostics, University Medical Center Maribor; Pauline Touche, Hôpital Necker-Enfants Malades, Paris; Julia Versavau and Vanessa Jacobs, Pediatric Gastroenteroloy, Université Catholique de Louvain, Cliniques universitaires Saint Luc, Brussels; Sabine Freitag, MSc, Department of Paediatrics, Medical University of Graz, Graz, Austria; Katharina Werjowkina, Pediatrics, St. Marien Hospital, Bonn, Germany; Reut Klein, MD, Institute of Gastroenterology, Nutrition \& Liver Diseases, Schneider Children's Medical Center, Sackler Faculty of Medicine, Tel Aviv University, Tel Aviv, Israel; Alexandrina Serban, Department National Institute for Mother and Child Health, Bucharest, Czech Republic; Stefania Bitetti, MD, Anthony Akobeng, MD, and Andrew Fagbemi, MD, Royal Manchester Children's Hospital, Manchester, UK; Valerie Vasseur, Hôpital Saint Vincent de Paul, Catholic University; Irina Zakharova, MD, PhD, Russian Medical Academy of Postgraduate Education; Maria Revnova, MD, PhD, and Elena Kornienko, MD, PhD, Saint-Petersburg Pediatric State Medical Academy; Alexandra Fabry-Said, MSc, Annecarin Brückner, BSc, MPH, Dana Popfinger, Ursula Weise, Astrid Hielscher, Christian Stelzl, Magdalena Widmann, Boglarka Szentes, and Anna Theisen, Dr. von Hauner Children's Hospital, Department of Pediatrics, University Hospital, LMU Munich, Munich Germany.

In particular, we thank all participating patients and their families.

Study registration: ProCeDE is registered at German Registry for Clinical Trials, Reg-No DRKS00003555.

\section{Conflicts of interest}

S. Koletzko received financial support to conduct this study in addition to nonprofit funding from the following industry partners: EUROIMMUN Medizinische Labordiagnostika AG (Luebeck, Germany), Eurospital SpA (Trieste, Italy), INOVA diagnostics (USA), Phadia-ThermoFisher (Sweden/ USA), R-Biopharm/Zedira (Darmstadt, Germany), and Dr. Schär Germany $\mathrm{GmbH}$ (Ebsdorfergrund, Germany). None of the other authors reported any conflicts of interest with respect to this study.

\section{Funding}

This study was funded by ESPGHAN (European Society of Pediatric Gastroenterology, Hepatology and Nutrition); Celiac Society of the United Kingdom "Coeliac UK"; Danish Celiac Society "Dansk Cøliakiforening"; Dutch Celiac Society "Nederlandse Coeliakie Vereniging"; Finnish Celiac Society "Keliakialiitto"; German Celiac Society "Deutsche Zöliakie Gesellschaft"; Hungarian Celiac Society "Liszterzekenyek Erdekkepviseletenek Orszagos Egyesulete"; Italian Celiac Society "Associazione Italiana Celiachia"; AOK Bayern (Public Health Insurance); and diagnostic industry partners EUROIMMUN Medizinische Labordiagnostika AG (Luebeck, Germany), Eurospital SpA (Trieste, Italy), INOVA diagnostics (USA), Phadia-ThermoFisher (Sweden/USA), R-Biopharm/Zedira (Darmstadt, Germany), and Dr. Schär Germany GmbH (Ebsdorfergrund, Germany). None of the funding partners had any influence on study design, data collection, analysis, interpretation, or writing of the manuscript. 